\title{
FUNGSI MEDIA ONLINE SEBAGAI MEDIA LITERASI BUDAYA BAGI GENERASI MUDA
}

\author{
Gita Aprinta E.B
}

(gita@usm.ac.id)

\section{Dosen Jurusan Ilmu Komunikasi, FTIK Universitas Semarang}

\begin{abstract}
Online media as an alternative media expected to fulfill the function of the mass media as the previous conventional media, among others, to meet the needs of information all at once into a medium that is able to educate its users. A website called www.palingindonesia.com seeks to encourage young people to participate actively to share the experience and knowledge of Indonesian culture through writing. Using a qualitative content analysis this study aims to identify the educational messages on website www.palingindonesia.com with the conception of internet and public sphere as a ground theory that focusing texts as an object. Mayring methods is choosen to analyze the text by combined lexico grammatical, context analysis, and intepretation. This study resulted a conclusion that the function of culture media literacy can be run on online media www.palingindonesia.com
\end{abstract}

Kata Kunci: media online, cultural literacy, generation iY, content analysis

\section{PENDAHULUAN}

Media online didefinisikan sebagai media yang menyajikan karya jurnalistik secara online. Sebagai sebuah hasil dari perkembangan teknologi komunikasi, media online menawarkan sebuah media yang dapat digunakan sebagai alat komunikasi antar manusia bagi para penggunanya. Hal ini dikarenakan media online memiliki beberapa sifat diantaranya adalah interaktif dan egaliter. Menjadi bagian dari media massa generasi ketiga, kemunculan media online di Indonesia diawali dari peristiwa lengsernya Orde Baru tahun 1998, dimana masyarakat membutuhkan sebuah media alternatif untuk menjawab kebutuhan akan informasi seketika, maka pada tahun itu pula munculah www.detik.com sebagai bentuk media online pertama di Indonesia.

Seperti media massa lainnya, media online juga memiliki dampak yang cukup kompleks terhadap budaya baik secara individu dan masyarakat. Laswell sendiri mengidentifikasi fungsi media massa pada budaya ke dalam empat elemen yaitu fungsi pengawasan, penghubungan, pentransferan budaya dan dua kategori. Hal ini diperkuat oleh pernyataan Marshall McLuhan yang mengatakan bahwa media massa berperan untuk membentuk karakter serta bidang sosial masyarakat, termasuk sosial budaya (McQuail, 2000:107)

Memiliki sifat yang cukup unik karena menggabungkan kemampuan cetak, audio, dan visual membuat media online 
memiliki nilai lebih dibandingkan media tradisional pada umumnya. Oleh karenanya, dengan kelebihan yang ditawarkan tersebut, memungkinkan pengguna dapat mengakses informasi secara lebih interaktif, sehingga menjadikan media online memiliki potensi untuk digunakan sebagai media pembelajaran, khususnya literasi mengenai budaya.

Budaya mengacu pada bentuk bahasa, kepercayaan, nilai, norma, ataupun kebiasaan yang menjadi gaya hidup salam suatu masyarakat tertentu. Budaya diwariskan dari generasi ke generasi melalui sebuah proses sosialisasi. Namun demikian tidak dapat dipungkiri jika masih banyak terdapat perbedaan mengenai definisi dan konsepsi budaya itu sendiri khususnya di kalangan generasi muda. Hal ini disebabkan oleh munculnya arus globalisasi yang ditandai dengan ekspansi besar-besaran terhadap industri budaya. Globalisasi dapat dipahami sebagai bertumbuhnya saling ketergantungan antara masyarakat diseluruh dunia terhadap penyebaran budaya yang sama, barang-barang konsumsi dan kepentingan ekonomi (Browne, 2008:36)

Arus globalisasi diiringi dengan perkembangan teknologi komunikasi seperti teknologi munculnya internet merubah pola masyarakat terhadap konsumsi infomasi. Melalui internet pula masyarakat memiliki keragaman pilihan budaya dan produk yang ingin dikonsumsi. Starbucks, McDonald, K-Pop, dan modern lifestyle, menjadi bagian yang tidak bisa dipisahkan dari generasi muda jaman sekarang. Produk dan budaya lokal menjadi sesuatu yang tidak lagi menarik, digantikan oleh produk budaya dan gaya hidup yang seragam diseluruh dunia, menyebar melalui kecanggihan teknologi komunikasi dan membentuk sebuah budaya global serta menghasilkan industri budaya baru yang melemahkan budaya nasional atau budaya lokal suatu negara.

Bagi sebuah bangsa, budaya nasional sama pentingnya dengan ideologi bangsa itu sendiri. Generasi muda adalah generasi yang diharapkan dapat melestarikan sebuah budaya untuk dapat diwariskan ke generasi berikutnya. Kekhawatiran bahwa budaya nasional akan tergerus oleh budaya global yang terus muncul seiring dengan perkembangan teknologi komunikasi merupakan sebuah issue yang perlu diperhatikan, mengingat bahwa konsumsi masyarakat terhadap internet meningkat tiap tahunnya. Di Indonesia sendiri, melalui sebuah survei yang dilakukan oleh UNICEF, sekitar 79\% dari 400 responden usia 10 - 19 tahun yang dikategorikan sebagai generasi muda adalah para 
pengguna internet aktif (Aditya Panji, 2014).

Generasi muda yang saat ini sedang memegang kendali dalam musnah atau tidaknya budaya nasional suatu bangsa adalah generasi yang Tim Elmore kategorikan sebagai generasi iY, yaitu generasi yang terlahir dari tahun 1995 sampai awal 2000an. Generasi ini tumbuh saat teknologi sedang berkembang pesat. Generasi iY ini akan melahirkan generasi $\mathrm{Z}$ dimana akses dan arus informasi menjadi tidak terbendung, sehingga terpaan budaya global menjadi sesuatu yang tidak lagi bisa dihindarkan.

Namun demikian, kemunculan internet dengan berbagai variannya, bukanlah sesuatu yang harus ditakuti. Dengan memanfaatkan kelebihan yang dimiliki oleh masing-masing fiturnya, contohnya media online, internet dapat dimanfaatkan untuk membantu generasi muda mengenal budaya nasional sekaligus menumbuhkan ketertarikan terhadap budaya bangsa mereka sendiri. Pergeseran tipe khalayak dari tipe khalayak positif pada masa media tradisional menuju tipe khalayak aktif adalah keuntungan lain yang dimiliki oleh media online. Bentuk hubungan antara media dan khalayak tidak lagi sekedar interaksi antara audiensi-media, melainkan khalayak diposisikan pada posisi negosiasi, dimana khalayak bisa menjadi konsumen sekaligus produsen pesan dirasa dapat memberikan kemudahan bagi berlangsungnya proses literasi budaya.

Literasi budaya penting untuk dilakukan sebagai benteng budaya atau filter terhadap hadirnya budaya luar atau budaya global agar tidak mengganggu proses enkulturasi budaya asal. Literasi budaya bukan hanya sekedar keahlian formal melainkan juga sebuah pengetahuan kanonis, yang diterjemahkan oleh Hirsch sebagai "knowledge upon literacy, and literacy upon cultural literacy" (Hirsch, 2002: 59 -73). Literasi budaya dapat dilakukan melalui berbagai media dan institusi, seperti sekolah, keluarga, tayangan televisi, dan melalui media online.

Adalah www.palingindonesia.com salah satu media online, yang menyajikan artikel-artikel mengenai keanekaragaman kebudayaan Indonesia. Situs yang merupakan bentuk dukungan salah satu provider telekomunikasi di Indonesia pada komunitas digital Komunitas Paling Indonesia untuk turut serta dalam upaya pelestarian budaya dan warisan keluhuran Indonesia. Komunitas Paling Indonesia telah berdiri sejak tahun 2011, merupakan sebuah komunitas kreatif anak-anak Indonesia yang melakukan upaya melalui dunia digital dan sosial media untuk mengumpulkan khazanah kekayaan 
budaya Indonesia. Pendekatan yang dilakukan oleh situs PalingIndonesia adalah dengan mengajak generasi muda untuk terlibat aktif dalam proses produksi sekaligus penyebaran konten.

Tulisan ini mencoba untuk mengidentifikasikan pesan-pesan edukatif yang ada dalam situs www.palingindonesia.com terkait dengan budaya nasional Indonesia sekaligus memenuhi fungsi media online yang dapat digunakan sebagai media literasi budaya bagi generasi muda.

\section{TINJAUAN TEORI}

Internet, Public Sphere dan Virtual Sphere

Konsep public sphere berangkat dari gagasan Habermas tentang sebuah ruang dimana masyarakat berdialog untuk mengeluarkan ide dan pendapat secara bebas. Sebuah ruang sosial yang dapat diakses oleh seluruh lapisan masyarakat (Habermas, 1989:102). Ranah publik memiliki karakteristik tertentu yang disebut oleh Habermas sebagai dimensi penting, yaitu, pembentukan opini publik, semua masyarakat memiliki akses, kebebasan untuk menuangkan pendapat berkaitan dengan kepentingan umum, dan debate over the general rules governing relations.
Internet yang digembor-gemborkan sebagai bentuk perkembangan paling penting dalam komunikasi kontemporer, memang menghasilkan ruang publik global dimana tiap individu mendapatkan akses langsung ke forum global dimana mereka dapat mengekspresikan argumen secara bebas (Ubayasiri, 2010:1). Percakapan terjadi dalam skala global setiap hari dengan siapapun di internet mengenai apa saja mulai dari hal-hal kecil sampai dengan lontaran kritik kepada pemerintah.

Namun demikian, pemikiran internet sebagai public sphere masih menjadi pro kontra sejumlah pemikir termasuk Habermas sendiri. Respon lambat ditunjukkan oleh Habermas mengenai peranan internet sebagai public sphere. Habermas menganggap bahwa dalam internet terjadi fragmentasi pada konteks komunikasi. Publik yang cenderung anonim dan banyaknya sebaran informasi dalam internet membuat masyarakat melakukan filter terhadap informasi atau issue yang ingin dikonsumsi sehingga membatasi keterlibatan masyarakat untuk berdiskusi dalam ruang publik.

Sementara itu, Dahlberg (dalam Ubayasiri 2010) berpendapat bahwa setidaknya ada enam kriteria yang harus dipenuhi oleh internet agar dapat dianggap 
sebagai public sphere. Keenam kriteria tersebut adalah:

1. Adanya otonomi negara dan kekuatan ekonomi

2. Pertukaran dan kritik dari masyarakat terkait klaim validitas moral praktis

3. Refleksivitas

4. Ideal roke taking

5. Ketulusan

6. Inklusi diskursif dan kesetaraan.

Mungkin lebih berarti apabila internet dilihat sebagai sebuah bentuk virtual sphere sebagai revitalisasi dari konsep public sphere Habermas. Pada dasarnya ketika internet menyediakan sebuah ruang publik, ia tidak harus menjadi ranah publik. Keluasan akses informasi yang ada pada media online tidak selalu harus mengarah pada partisipasi politik. Keuntungan internet sebagai ruang publik dapat dinikmati sebagai sebuah akses untuk terhubung, menikmati percakapan, dan menyerap informasi yang disajikan. Dalam internet atau media online memungkinkan terjadinya sebuah diskusi yang menghubungkan publik untuk dapat berbagi pengalaman yang sama sekaligus memproduksi perbedaan budaya (Papachrissi, 2002: 12)

\section{Literasi Budaya}

Keaksaraan budaya atau melek budaya adalah pengetahuan tentang sejarah, kontribusi dan perspektif dari kelompok budaya yang berbeda, termasuk kelompok sendiri, yang dibutuhan untuk membaca, menulis, dan lainnya. Literasi budaya memerlukan interaksi dengan budaya dan merefleksikan budaya tersebut. Literasi budaya berakar pada berbagai macam pengetahuan yang digunakan untuk menjalin komunikasi, penerimaan, dan pemahaman dalam masyarkat global yang dinamis (Desmond, 2011).

Literatur dan media mempunyai pengaruh yang signifikan dalam menyebarkan informasi mengenai budaya tertentu, namun tanpa adanya pemahaman dan literasi budaya, maka informasi hanya sekedar menjadi informasi. Itu sebabnya dikatakan oleh Polistina, bahwa literasi budaya merupakan sesuatu yang cukup penting karena dapat ditemukan dalam berbagai konteks.

\section{METODE PENELITIAN}

Analisis isi kualitatif dipilih oleh penulis sebagai metode untuk dapat mengidentifikasi pesan edukatif yang ada dalam situs www.palingindonesia.com. Analisis isi kualitatif adalah sebuah pendekatan empiris, metodologis dikendalikan oleh analisis teks dalam konteks komunikasi, dengan mengikuti 
aturan dan langkah langkah dari model analisis isi tanpa perhitungan kuantitas (Mayring, 2002:2). Penggunaan analisis model Mayring dirasa paling tepat dikarenakan dalam model ini, terdiri dari serangkaian teknik untuk menganalisa teks secara sistematis. Teks yang dianalisa adalah teks teks terkait penyebaran informasi mengenai budaya Indonesia yang ada dalam situs Paling Indonesia.

Sebagai langkah pertama, ditentukan dulu definisi lexico grammatical susunan tata bahasa sebuah teks, kemudian ditentukan materi yang akan dijelaska dan diikuti dengan analisis konteks secara sempit dan secara luas, setelah itu dilakukan intepretasi terhadap teks.. Intepretasi teks tersebut merupakan hasil akhir dari analisa. Teks yang dianalisa dibatasi pada postingan yang menggambarkan mengenai definisi budaya yaitu pada karya, nilai, kebiasaan, gagasan, dan gaya hidup. Oleh karenanya dipilih dua teks yang dirasa mewakili pengertian budaya.

\section{Paling Indonesia

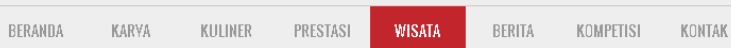 \\ Home , Wista " Ritual Pelebon (Kremasi) Puri Agenng Ubud-Bali Libatkan Ribuan Masyrakat}

RITUAL PELEBON (KREMASI) PURI AGUNG UBUD-BALI LIBATKAN RIBUAN MASYARAKAT

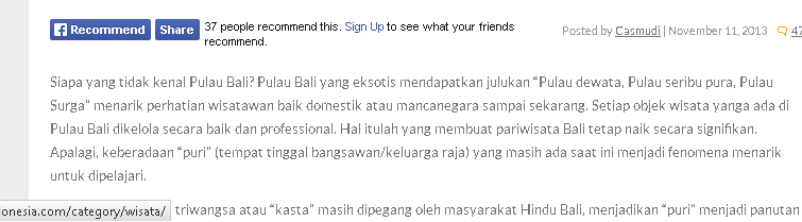

Gambar 1. Unit Analisa Teks

\section{Paling Indonesia

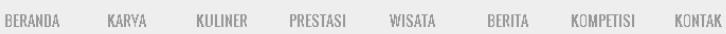

Home ; KarYa ; KEEUDAYAAN EBEG JAWA YANG PERLU DI KENALKAN PADA DUNIA

\section{KEBUDAYAAN EBEG JAWA YANG PERLU DI KENALKAN PADA DUNIA}

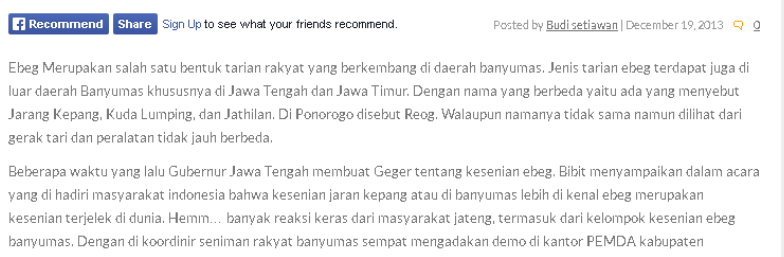

Gambar 2. Unit Analisa Teks

\section{TEMUAN dan PEMBAHASAN}

a. Artikel Ritual Palebon (Kremasi) Puri

Agung Ubud - Bali Libatkan Ribuan

Masyarakat

1. Ringkasan

Tahapan pertama yang dilakukan dalam analisis ini adalah membuat ringkasan teks tanpa mengubah material asli teks tersebut. Ringkasan dapat dibuat 
menjadi sebuah parafrase. Dalam tulisan berjudul Ritual Palebon (Kremasi) Puri Agung Ubud-Bali Libatkan Ribuan Masyarakat, ringkasan teks secara keseluruhan dalam bentuk parafrase yang disusun berdasarkan urutan dari paragraf 1

- 10 adalah sebagai berikut:

"Bali adalah sebuah pulau yang sangat terkenal di seluruh dunia. Setiap bagian di pulau Bali mempunyai daya tarik tersendiri untuk dikelola menjadi sebuah objek wisata secara profesional, termasuk tempat tempat yang memiliki sejarah seperti puri atau tempat tinggal keluarga raja

Dalam kebudayaan Bali, pembagian strata sosial masih sangat kental. Ksatria merupakan strata sosial paling tinggi di Bali dan biasanya dimiliki oleh keluarga kerajaan. Strata ini sangat dihormati oleh masyarakat Hindu Bali

Jika ada anggota keluarga dalam strata Ksatria meninggal, maka akan diadakan sebuah upacara yang disebut sebagai "Sakral Puri". Upacara Sakral Puri adalah serangkaian upacara kematian yang melibatkan ribuan masyarakat Bali, terdiri dari upacara pembaringan jenazah dan pembakaran jenazah/palebon.
Rangkaian upacara pertama, jenazah akan dibaringkan pada sebuah tempat yang dilengkapi dengan barang-barang kesukaan mendiang semasa hidupnya. Setelah itu keluarga dibantu masyarakat akan membuat palebon dengan ukuran tertentu sebagai tempat kremasi atau pembakaran jenazah.

Sebelum upacara pembakaran jenazah dimulai, maka akan ada upacaraupacara sisipan seperti upacara Nanceb, Ngingsirang Layo dan Mendak. Upacara Nanceb dimaksudkan untuk memilih hari baik, upacara Ngingsirang Layo adalah upacara memindahkan jenazah ke bangunan terbuka. Sementara Mendak adalah sebuah upacara permohonan kepada Yang Maha Kuasa agar roh yang meninggal dapat dibebaskan. Sesudahnya jenazah akan dibawa ke setra/kuburan dan dilakukan upacara pembakaran.

Palebon biasanya menyita perhatian masyarakat dan wisatawan secara luas sehingga kemudian ditetapkan oleh pemerintah sebagai salah satu bentuk kearifan lokal"

\section{Eksplikasi}

Pada tahapan ini akan dilakukan penjelasan, pengklarifikasian, dan penganotasian materi. 


\begin{tabular}{|c|c|c|c|c|c|}
\hline No & $\begin{array}{l}\text { Lexico } \\
\text { Grammatical }\end{array}$ & Teks & $\begin{array}{l}\text { Analisis Konteks } \\
\text { Secara Sempit }\end{array}$ & $\begin{array}{l}\text { Analisis Konteks Secara } \\
\text { Luas }\end{array}$ & Explicatory Parafrase \\
\hline 1 & $\begin{array}{l}\text { Mendeskripsikan } \\
\text { tempat }\end{array}$ & $\begin{array}{l}\text { Pulau Dewata, Pulau seribu } \\
\text { pura, pulau surga }\end{array}$ & $\begin{array}{lr}\text { Bali } & \text { dikenal } \\
\text { sebagai } & \text { pulaunya } \\
\text { para } & \text { dewa, } \\
\text { memiliki } & \text { ribuan } \\
\text { pura } & \\
\end{array}$ & $\begin{array}{l}\text { Bali memiliki beragam } \\
\text { obyek wisata menarik } \\
\text { termasuk tempat tempat } \\
\text { bersejarah }\end{array}$ & $\begin{array}{l}\text { Mendeskripsikan Bali sebagai } \\
\text { sebuah tempat tujuan wisata } \\
\text { yang menarik }\end{array}$ \\
\hline 2 & $\begin{array}{l}\text { Mendeskripsikan } \\
\text { sejarah dalam wisata } \\
\text { Bali }\end{array}$ & $\begin{array}{l}\text { Kuatnya pembagian triwangsa } \\
\text { atau "kasta" masih dipegang } \\
\text { oleh masyarakat Hindu Bali, } \\
\text { menjadikan "puri" menjadi } \\
\text { panutan masyarakat dalam } \\
\text { melakukan ajaran agama } \\
\text { Hindu. }\end{array}$ & $\begin{array}{l}\text { Terdapat perbedaan } \\
\text { strata sosial di } \\
\text { kalangan } \\
\text { masyarakat Hindu } \\
\text { Bali }\end{array}$ & $\begin{array}{l}\text { Pembagian strata sosial } \\
\text { telah ada sejak jaman } \\
\text { dahulu kala sebagai bagian } \\
\text { dari tradisi dan budaya } \\
\text { masyarakat Bali }\end{array}$ & $\begin{array}{l}\text { Sejarah menjadi bagian penting } \\
\text { dari masyarakat Bali yang tidak } \\
\text { dapat terpisahkan, dan terwujud } \\
\text { dalam setiap kehidupan sehari- } \\
\text { hari masyarakat Bali. }\end{array}$ \\
\hline 3 & $\begin{array}{l}\text { Mendeskripsikan } \\
\text { adat istiadat }\end{array}$ & $\begin{array}{l}\text { - Ritual sakral puri yang } \\
\text { paling menarik dan menjadi } \\
\text { objek wisata adalah ritual } \\
\text { pelebon/kremasi } \\
\text { (pembakaran mayat) } \\
\text { keluarga Puri Agung Ubud, } \\
\text { Gianyar - Bali } \\
\text { - diadakan berbagai upacara } \\
\text { skaral diantaranya: upacara } \\
\text { Nanceb, Nuasen lan } \\
\text { Negtegan Karya yang } \\
\text { bermakna memilih hari yang } \\
\text { baik untuk mempersiapkan } \\
\text { seluruh keperluan upacara } \\
\text { agar segala hal bisa berjalan } \\
\text { lancar, tanpa adanya }\end{array}$ & $\begin{array}{lr}\text { Ritual sakral puri } \\
\text { adalah } & \text { ritual } \\
\text { kremasi } & \text { bagi } \\
\text { keluarga } & \\
\text { bangsawan atau } \\
\text { strata tertinggi } \\
\text { masyarakat Bali }\end{array}$ & $\begin{array}{l}\text { Ritual ini menjadi sebuah } \\
\text { adat istiadat yang } \\
\text { dijalankan turun temurun } \\
\text { dengan serangkaian } \\
\text { upacara yang diadakan } \\
\text { untuk mengantar mendiang } \\
\text { ke peristirahatan terakhir. }\end{array}$ & $\begin{array}{l}\text { Ritual sakral puri adalah sebuah } \\
\text { bentuk adat istiadat yang telah } \\
\text { menjadi tradisi bagi masyarakat } \\
\text { Bali }\end{array}$ \\
\hline
\end{tabular}




\begin{tabular}{|c|c|c|c|c|c|}
\hline & & $\begin{array}{l}\text { halangan baik secara sekala } \\
\text { maupun niskala. Upacara } \\
\text { Ngingsirang Layon } \\
\text { (memindahkan jenazah) dari } \\
\text { ruangan tempat beliau } \\
\text { disemayamkan di Gedong } \\
\text { (yang merupakan ruangan } \\
\text { tertutup) ke Bale Gede } \\
\text { (bangunan terbuka). }\end{array}$ & & & \\
\hline
\end{tabular}


Teks diatas merepresentasikan

bagaimana sebuah upacara palebon/pembakaran mayat di Bali menjadi bagian dari budaya. Berangkat dari pembagian kasta yang diyakini oleh masyarakat sebagai bagian dari sejarah pembentukan masyarakat dan adat istiadat mereka. Tulisan ini memuat pesan-pesan edukatif salah satunya mengenai nilai gotong royong, yang tidak hanya ada di Bali melainkan hampir di seluruh penjuru Indonesia. Gotong royong menjadi sebuah nilai yang diyakini sebagai bentuk kepedulian dan tanggung jawab masyarakat sebagai makhluk sosial.

Percakapan dalam kolom komentar menunjukkan bahwa, banyak pembaca, kurang lebih 47 orang mendapatkan informasi yang menarik tentang upacara palebon yang ada di Bali. Beberapa di antaranya mengemukakan pendapat bahwa tulisan yang ditulis oleh Casmudi tersebut membuka wawasan mengenai khazanah kebudayaan Indonesia, sebagaimana yang tertera dibawah ini:

\section{Eksplikasi}




\begin{tabular}{|c|c|c|c|c|c|}
\hline No & $\begin{array}{l}\text { Lexico } \\
\text { Grammatical }\end{array}$ & Teks & $\begin{array}{l}\text { Analisis Konteks } \\
\text { Secara Sempit }\end{array}$ & $\begin{array}{l}\text { Analisis Konteks Secara } \\
\text { Luas }\end{array}$ & Explicatory Parafrase \\
\hline 1 & Identifikasi Budaya & $\begin{array}{l}\text { Ebeg Merupakan salah satu } \\
\text { bentuk tarian rakyat yang } \\
\text { berkembang di daerah } \\
\text { banyumas. Jenis tarian ebeg } \\
\text { terdapat juga di luar daerah } \\
\text { Banyumas khususnya di Jawa } \\
\text { Tengah dan Jawa Timur. }\end{array}$ & 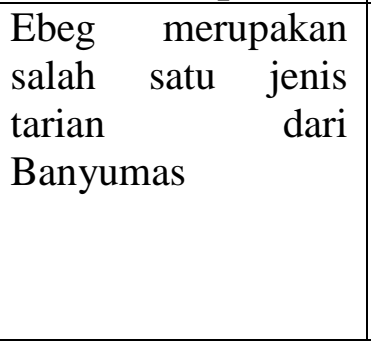 & $\begin{array}{lcr}\text { Tarian merupakan } & \text { salah } \\
\text { satu bentuk budaya } \\
\text { nasional yang hampir } \\
\text { setiap daerah miliki }\end{array}$ & $\begin{array}{l}\text { Ebeg menjadi bagian dari } \\
\text { budaya masyarakat Banyumas }\end{array}$ \\
\hline 2 & $\begin{array}{l}\text { Mendeskripsikan } \\
\text { sejarah budaya }\end{array}$ & $\begin{array}{l}\text { Namun kalau melihat } \\
\text { perkembangan sejarah, ebeg } \\
\text { merupakan jenis tarian rakyat } \\
\text { yang cukup tua umurnya. } \\
\text { Lahir di tengah-tengah rakyat } \\
\text { pedesaan dan jauh dari istana. } \\
\text { Masyarakat kediri dan malang } \\
\text { umumnya berpendapat bahwa } \\
\text { jaran kepang lahir sejak } \\
\text { zaman kerajaan Kediri. Atau } \\
\text { paling lambat sejak awalnya } \\
\text { kerajaan majapahit. Jaran } \\
\text { kepang itu lambang } \\
\text { kegagahan Raden } \\
\text { Panjikudhawenengpati disaat } \\
\text { menaiki kuda. }\end{array}$ & 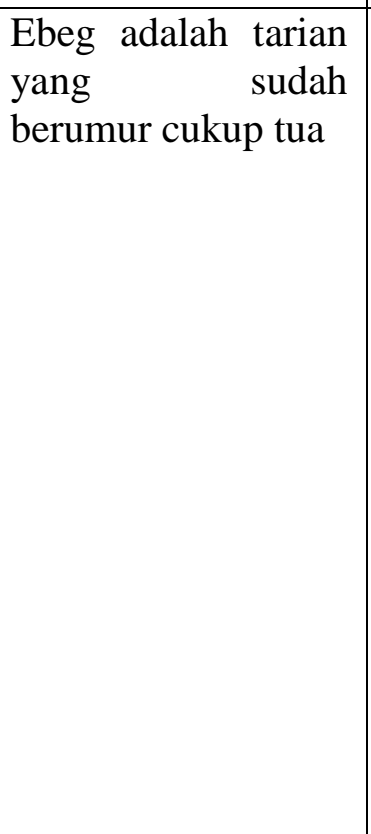 & $\begin{array}{l}\text { Tarian Ebeg merupakan } \\
\text { tarian yang melambangkan } \\
\text { sejarah kerajaan Majapahit, } \\
\text { sebagai sebuah simbol }\end{array}$ & $\begin{array}{l}\text { Ada banyak versi terkait dengan } \\
\text { kelahiran tari Ebeg, namun } \\
\text { tarian Ebeg merupakan tarian } \\
\text { yang sudah ada sejak jaman } \\
\text { kerajaan Majapahit }\end{array}$ \\
\hline 3 & Entitas Tarian & \begin{tabular}{lrr} 
Masyarakat & \multicolumn{2}{c}{ Banyumas } \\
berpendapat & bahwa $\quad$ ebeg
\end{tabular} & $\begin{array}{lr}\text { Tarian yang } & \text { sangat } \\
\text { dihormati } & \text { oleh } \\
\end{array}$ & $\begin{array}{l}\text { Selain sebagai } \text { karya } \\
\text { budaya, juga sebagai unsur }\end{array}$ & Simbol Keagamaan \\
\hline
\end{tabular}




\begin{tabular}{|c|c|c|c|c|c|}
\hline & & $\begin{array}{l}\text { dahulunya merupakan tarian } \\
\text { sakral yang biasa di ikut } \\
\text { sertakan dalam upacara } \\
\text { keagamaan }\end{array}$ & $\begin{array}{l}\text { masyarakat } \\
\text { Banyumas }\end{array}$ & $\begin{array}{l}\text { yang harus ada dalam } \\
\text { upacara keagamaan. } \\
\text { Budaya dan agama berjalan } \\
\text { beriringan }\end{array}$ & \\
\hline 4 & $\begin{array}{l}\text { Budaya sebagai } \\
\text { refleksi kehidupan } \\
\text { masyarakat }\end{array}$ & $\begin{array}{l}\text { Setiap regu jarang kepang } \\
\text { terdiri dari } 2 \text { kelompok } \\
\text { dengan } 2 \text { orang pemimpin. } \\
\text { Ada dua warna kuda putih } \\
\text { dan kuda hitam. Kuda yang } \\
\text { berwarna } \\
\text { menggambarkan pemimpin } \\
\text { yang menuju kebenaran sejati. } \\
\text { Sedangkan kuda berwarna } \\
\text { hitam menggambarkan } \\
\text { pemimpin yang menuju } \\
\text { kejahatan. Pada trik-trik } \\
\text { tertentu dalam permainan } \\
\text { kedua pemimpin itu bertemu } \\
\text { dan saling menggelengkan } \\
\text { kepala. Hal ini menunjukan } \\
\text { bahwa antara kebenaran dan } \\
\text { kejahatan tak dapat bertemu. }\end{array}$ & $\begin{array}{lr}\text { Gambaran } & \text { tarian } \\
\text { Ebeg dan lambang- } \\
\text { lambang } & \text { yang } \\
\text { digunakan } & \text { sebagai } \\
\text { perwakilan } & \text { bentuk } \\
\text { kejahatan } & \text { dan } \\
\text { kebaikan } & \end{array}$ & $\begin{array}{l}\text { Budaya pada dasarnya } \\
\text { merupakan sebuah refleksi } \\
\text { kehidupan bermasyarakat } \\
\text { sehari-hari. Penanaman } \\
\text { nilai dilakukan melalui } \\
\text { bentuk karya/estetika yang } \\
\text { dapat dinikmati oleh semua } \\
\text { orang. Sehingga penetrasi } \\
\text { mengenai nilai nilai } \\
\text { kehidupan dapat secara } \\
\text { halus dilakukan tanpa } \\
\text { paksaan }\end{array}$ & Visualisasi tarian \\
\hline
\end{tabular}


Teks diatas menjelaskan bahwa sebuah tarian dapat menjadi bentuk identifikasi masyarakat tertentu. Tarian Ebeg bukan sekedar sebuah karya keindahan, melainkan sebuah karya yang terbentuk dari sejarah panjang masyarakat Banyumas. Sudah ada sejak jaman kerajaan Majapahit, dipercaya sebagai lambang kegagahan kerajaan. Dianggap sakral dan sering digunakan dalam upacara keagamaan.

Sebuah budaya tumbuh dan berkembang di sebuah masyarakat bukan tanpa sebab, sebagaimana tradisi Palebon, tarian Ebeg juga memuat nilai-nilai yang lekat dalam kehidupan masyarakat Banyumas sehari-hari. Pesan edukatif yang hendak diberikan melalui tulisan ini adalah, bagaimana sebuah tarian menjadi refleksi kehidupan masyarakat mengenai kejahatan dan kebaikan. Penggambaran struktur tarian Ebeg, memperkenalkan kepada masyarakat khususnya generasi muda, bahwa Indonesia mempunyai beragam tarian yang mengandung nilainilai filosofis kehidupan.

Tarian yang tampil sebagai bentuk kesenian didukung oleh bentuk kesenian lain seperti musik dan gaya pakaian menggambarkan keragaman budaya seperti yang tertulis dibawah ini-

Ciri-ciri ebeg banyumas antara lain; memakai mahutha, pakainnya lebih tertutup dan di iringi lagu-lagu banyumasan, Iringan gending-gending tersebut biasanya yaitu : Ricik-ricik, Lung Gadung, Blendhong, Gudril, Elingeling yang menjadi andalan dalam setiap pentas ebeg banyumasan dan lagu lainnya.

Media online memberikan ruang yang cukup luas bagi berlangsungnya proses literasi budaya sebagaimana yang dipaparkan oleh Papacharissi, bahwa sebagai sebuah virtual sphere, media online memiliki 3 kelebihan dalam hal akses informasi, resiprokasi komunikasi, dan komersialisasi (Papachrissi, 2002: 8). Akses informasi yang mudah akan mendorong seseorang untuk dapat terlibat dalam partisipasi memperkenalkan budaya nasional melalui tulisan yang dapat dibaca oleh siapapun. Selain itu model two way communication yang melengkapi media online akan memudahkan khalayak untuk terlibat secara interaktif sehingga proses literasi budaya dapat tersampaikan melalui pengalaman berbagi budaya.

Percakapan yang terjadi secara interaktif melibatkan komunikasi dua arah, memberikan timbal balik pada topik yang sedang dibicarakan yang dapat menghubungkan generasi muda sehingga memproduksi pengetahuan dan pemahaman bersama mengenai budaya. Dengan demikian literasi budaya dapat tersampaikan melalui pengalaman berbagi budaya, tidak sekedar pada literatur 
semata. Pengalaman berbagi inilah yang akan memperkuat pemahaman seseorang mengenai suatu budaya, kemudian memberikan kesadaran mengenai nilai budaya nasional yang dimiliki. Pesan edukatif terprenetasi melalu interaksi interaktif antar pengguna yang terjadi melalui kolom komentar.

Media online memiliki kemampuan untuk mentransmisikan informasi ke generasi muda dan menjadi media pengembangan bagi pendidikan melek budaya, karena media online khususnya www.palingindonesia.com merupakan sebuah situs komunitas di mana masingmsing orang dapat mewartakan informasi, berbagi pengalaman budaya, pendapat dan gagasan, menyalurkan aspirasi dalam bentuk tulisan maupun gambar. Seperti yang dikatakan oleh Hobbs (1998) yang melihat literasi sebagai kemampuan untuk mengakses, menganalisis, mengevaluasi, dan mengkonsumsi pesan dalam berbagai bentuk. Dengan demikian media online dapat memenuhi perananya sebagai media untuk mentransmisi warisan sosial dari satu generasi ke generasi lainnya.

Sementara forum diskusi dalam kolom komentar menjadi media bagi generasi muda untuk lebih kritis, aktif, dalam memperoleh pemahaman mengenai budaya nasioonal, karena sesungguhnya proses literasi budaya bersifat aktif, terpusat pada warga belajar, dan partisipatoris (Buckingham \& Domaille, 2002)

\section{KESIMPULAN}

Media online menciptakan ruang bagi proses literasi budaya untuk generasi muda melalui beberapa kelebihan yang dimilikinya seperti akses internet dan komunikasi dua arah. Sebagai sebuah ruang publik, media online memberikan kesempatan bagi masyarakat untuk terlibat aktif dalam proses melek budaya melalui tulisan dan diskusi interaktif. Teks yang termuat dalam situs www.palingindonesia.com menampilkan pesan-pesan edukatif terkait dengan pengalaman budaya dan dibagikan untuk memperkaya khazanah pemahaman budaya generasi muda. Melalui situs ini pulalah, media online yang merupakan media alternatif mencoba untuk memenuhi fungsinya sebagai media pembelajaran masyarakat.

Saran dari penulis, agar melakukan identifikasi pesan edukatif melalui metode analisa teks yang lebih luas seperti semiotika, sehingga dapat didapatkan hasil yang lebih signifikan terkait dengan penelitian di atas 


\section{DAFTAR PUSTAKA}

Browne, John. (2002). Creating a Cultural Identity. Charlottesville, VA: University of Virgina Press

Buckingham, D., \& Domaille, K. (2002).

Where Are We Going and How Can We

Get There? General Finding From The

UNESCO Youth Media Education Survey

2001. London: Institute of Education

University of London.

Hirsch, E.D (2002). The New Dictionary of Cultural Literacy (3rd ed). New York: Houghton Mifflin

McQuail, Dennis

\section{Artikel dalam Jurnal Ilmiah}

Papachrissi, Zizi (2002). The virtual sphere: the internet as a public sphere. New Media Society, 4(1):9-27

Mayring, Phillip (2000). Qualitative Content Analysis. Forum Qualitative Social Research, 7(1): 21

\section{Proceedings Seminar atau Simposium}

Ubayasiri, Kasum (2010). The Internet and

Public Sphere. Queensland: Central Queensland University Press.

\section{Sumber Elektronik / Internet}

Aditya Panji (2014). Hasil Survei Pemakaian Internet Remaja Indonesia (http://tekno.kompas.com/read/2014/02/19 /1623250/Hasil.Survei.Pemakaian.Internet. Remaja.Indonesia, diakses tanggal 3 September 2014, pukul 21.07) Dahlberg, Lincoln. (2001). Extending the public sphere through cyberspace: The case of Minnesota E-democracy. Diakses 5 September 2014, dari www.firstmonday.org/issues/issue6_3/dahl berg/index.html\#note2 Hobbs, R. (1998). Instructional Practices in Media Literacy and Their Impact on Students Learning. Diakses 9 September, 2014, dari www.interact.uoregon.edu/MediaLit/ readingarticles/hobbs/inspractice.html 